however, very soon cried, and did not appear to be very materially injured, but, a day or two afterwards, fell into a strange, languid state; it revived, but at intervals sank into its former languor, and breathed very faintly, and died about the sixth day."

Mr. Hey of Leeds communicated to Dr. Underwood the notes of a case of an infant, which, born at full time, lay moaning and languid for four or five hours, and was then seized with a fainting fit, in which it continued for half an hour. It had ceased to breathe, except now and then giving a gasp or sob, and was as pale as a corpse. There was, however, a sensible pulsation of the heart, though feeble and slow ; but whether the circulation had been kept up all the time previous to his (Mr. Hey's) visit, could not be ascertained. The child was revived by the use of stimalants, but had three other similar attacks in the course of the day, though it had slept composedly between whiles, and sucked at the breast. It had seven more fainting fits in the night. The infant became a very healthy child.

On the fourth day of the existence of my patient, that portion of the integument outside the ligature showed signs of vitality having ceased in it; and on the fifth day it came away, leaving a round evenly cut wound in the skin of the abdomen, surrounded by a ring of inflammatory redness.

All the time of my attendance (nine days), the child did well; had no untoward symptom; and the wound was healing rapidly when I took leave of my patients.

9, Lupus Street, Belgravia, S.W.

\title{
Transactions of 迶rantbes.
} syncope of the child by which it was prevented from feeling any pain. It was tied so effectually that the thread did not slip off, nor was disturbed when the child began to cry and move.

No ill effects obtained to the mother, and the placenta was easily removed.

As the case I have described is of extreme rarity, and as $I$ do not know of even one similar to it being on record, I have thought it fit to bring forward.

The treatment in this case was extremely simple: first, because of the syncope into which the child fell; and secondly, because of the lax condition of the abdominal integuments affording an opportunity of securing the ligature tightly.

I need not here dwell upon the difficulty usually attendant upon deligating the integuments surrounding the umbilical aperture in the abdomen when the accident of which I speak has occurred, inasmuch as it must be impressed upon the mind of each of those practitioners who have been consulted in such circumstances.

Syncope in infants is a rare occurrence. I mean true syncope resulting from concussion of the brain, and not merely that imperfect state of animation which so often obtains at birth, and is manifested by feeble action of the heart, and an uncertain state of the entire system, which, as it were, oscillates between life and death. A condition of coma, or semicoma, is by no means so infrequent. One case of complete coma occurring in the infant at birth, as the result of compression during labour, and lasting for two days, then terminating in death, has recently come under my notice.

"Only in one instance," says Dr. Underwood, "have I seen anything at all resembling the true syncope after the living powers have once prevailed. In this case, the child was born at the instant its mother was moving from her chair into her bed, and, in consequence, fell with violence on the floor; it,

\section{EAST ANGLIAN BRANCH.}

ON MELASMA AND ALLIED AFFECTIONS.

By Peter Eade, M.D.Lond., M.R.C.P., Physician to the Norfolk and Norwich Hospital, etc.

[Read June 29th, 1866.]

I AM well aware how valuable is our time to-day, and how few minutes can be allotted to any one communication. I have therefore sought to compress the subject matter of my paper into as short a compass as is possible consistent with intelligibility. The purport of it is, to call attention to the subject of diseased pigmentary discoloration of the skin, and the supposed origin of this in disorder of the great centres of the sympathetic nervous system of the abdomen; and, after recording two cases of such discoloration, to add a few remarks upon some forms of that obscure but intractable disorder, which, for want of a definite knowledge of its nature, we are content to designate from its most striking symptom, and to term general debility; suggesting therefrom analogies to show the possibility of the origin of this and some other diseases in disorder of the same nervous centres.

I think, sir, I may venture to assert that the profession to which we have the honour to belong now thoroughly recognises the services which Dr. Addison rendered to the cause of medical knowledge, when he discovered and called attention to that remarkable bronzing of the skin and that special train of symptoms which accompanies this, which together are now so generally known by the name of melasma, melanopathia, or Addison's disease. No less are professional thanks due to Dr. Wilks, for the zeal and 